\title{
A new thermal gradient ice nucleation diffusion chamber instrument: design, development and first results using Saharan mineral dust
}

\author{
G. Kulkarni $^{1, *}$, S. Dobbie ${ }^{1}$, and J. B. McQuaid ${ }^{1}$ \\ ${ }^{1}$ School of Earth and Environment, University of Leeds, Leeds, UK \\ *now at: Atmospheric Science and Global Change Division, Pacific Northwest, National Laboratory, Richland, WA, USA
}

Received: 1 December 2008 - Published in Atmos. Meas. Tech. Discuss.: 30 January 2009

Revised: 16 April 2009 - Accepted: 4 May 2009 - Published: 11 June 2009

\begin{abstract}
A new Thermal Gradient ice nucleation Diffusion Chamber (TGDC) capable of investigating ice nucleation efficiency of atmospherically important aerosols, termed Ice Nuclei (IN), has been designed, constructed and validated. The TGDC can produce a range of supersaturations with respect to ice $\left(\mathrm{SS}_{i}\right)$ over the temperature range of -10 to $-34^{\circ} \mathrm{C}$ for sufficiently long time needed to observe the ice nucleation by the particles. The novel aspect of this new TGDC is that the chamber is run in static mode with aerosol particles supported on a Teflon substrate, which can be raised and lowered in a controlled way through the $\mathrm{SS}_{i}$ profile within the chamber, and nucleation events are directly observed using digital photography. The TGDC consists of two ice coated plates to which a thermal gradient is applied to produce the range of $\mathrm{SS}_{i}$. The design of the TGDC gives the ability to understand time-related ice nucleation event information and to perform experiments at different temperatures and $\mathrm{SS}_{i}$ conditions for different IN without changing the thermal gradient within the TGDC. The temperature and $\mathrm{SS}_{i}$ conditions of the experimental system are validated by observing $\left(\mathrm{NH}_{4}\right)_{2} \mathrm{SO}_{4}$ deliquescence and the results are in good agreement with the literature data. First results are presented of the onset ice nucleation for mineral dust sampled from the Saharan Desert, including images of nucleation and statistical distributions of onset ice nucleation $\mathrm{SS}_{i}$ as a function of temperature. This paper illustrates how useful this new TGDC is for process level studies of ice nucleation and more experimental investigations are needed to better quantify the role of ice formation in the atmosphere.
\end{abstract}

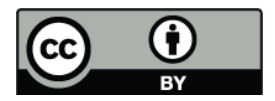

Correspondence to: G. Kulkarni (gourihar.kulkarni@pnl.gov)

\section{Introduction}

Aerosols affect the climate system by changing cloud characteristics by acting as cloud condensation nuclei (CCN) and ice nuclei (IN) (Twomey, 1974; Baker, 1997; Pruppacher and Klett, 1997). Lau and Wu (2003) found that more than 50\% of the earth's precipitation originates via the ice phase. Ice formation in the atmosphere may result from both homogeneous freezing of solution droplets formed from soluble $\mathrm{CCN}$ at temperatures below $-38^{\circ} \mathrm{C}$ and heterogeneous freezing of ice by insoluble or partially insoluble particles called IN. Compared to homogeneous freezing, far lower $\mathrm{SS}_{i}$ and warmer temperatures are needed for heterogeneous freezing of IN (Rogers and Yau, 1989). The heterogeneous freezing mechanism can take place (Vali, 1985) via direct deposition from vapor to ice on a suitable nucleus (deposition nucleation); and via freezing of previously condensed supercooled water or haze droplets (contact, condensation, and immersion ice nucleation).

Laboratory studies dealing with deposition ice nuclei have been undertaken since the 1950s but there remains a shortage of information on IN active fraction as a function of time and properties of IN acting as deposition ice nuclei in the atmosphere (Mason and Maybank, 1958; Roberts and Hallett, 1967; Schaller and Fukuta, 1979; Archuleta et al., 2005; Twohy and Poellot, 2005; Kanji and Abbatt, 2006; Möhler et al., 2006; Bundke et al., 2008). In the laboratory, the number of aerosols that activate as IN are measured by exposing an aerosol sample to a known temperature and precisely adjustable level of $\mathrm{SS}_{i}$. Standard light scattering methods are often used to detect the ice nucleation of the IN. In the past, laboratory experiments were performed using various

Published by Copernicus Publications on behalf of the European Geosciences Union. 


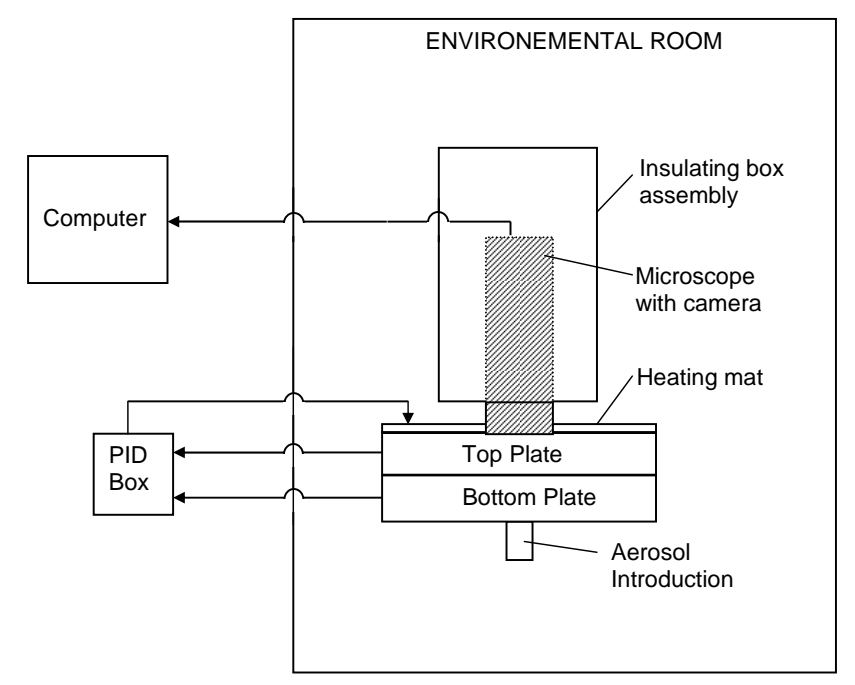

Fig. 1. Schematic diagram of the TGDC experimental set-up.

ice nucleation chamber designs, and temperature and $\mathrm{SS}_{i}$ conditions, to study the deposition ice nucleation of particles. For example, the flow cell design (Kanji and Abbatt, 2006) controlled the amount of water vapor pumped into the cell and the temperature inside the cell so that the desired $\mathrm{SS}_{i}$ value was achieved. Two other approaches are based on the type of aerosol flow mode used: continuous (Rogers, 1988; Salam et al., 2006; Stetzer et al., 2008) and static (Bailey and Hallett 2002) thermal gradient diffusion chamber. Here the desired $\mathrm{SS}_{i}$ profile is achieved by maintaining two parallel ice coated surfaces at different temperatures. The water vapor diffusion occurs from warmer to colder ice coated surface, and the maximum $\mathrm{SS}_{i}$ occurs approximately midway between the two surfaces because of the non-linear function of water vapor pressure and temperature.

In this paper we present a new concept for an ice nucleation chamber, based on the standard thermal gradient diffusion chamber in which a static diffusion design is adopted. Our new chamber allows different aerosol particles to be exposed to part or the full range of $\mathrm{SS}_{i}$ produced in the chamber, with a time resolution sufficient for heterogeneous ice nucleation to occur, without varying the temperature gradient between the two ice coated parallel plates. This reduces the uncertainty in terms of temperature and $\mathrm{SS}_{i}$ while repeating the experiments and assessing the spread of onset activation thresholds within each single sample of IN. The newly developed TGDC also allows experimentation with the same aerosols at various $\mathrm{SS}_{i}$ for the required length of time. It is planned to make use of this feature in the future to investigate the "memory effects" or "pre-activation" of atmospherically relevant IN (Turnbull, 1950; Roberts and Hallett, 1967). Another unique feature of the TGDC is a continuous supply of water vapor for long enough time for at least $10 \mathrm{~min}$ to detect the ice nucleation events, see Sect. 3 for more details.
Table 1. Specifications of the TGDC.

1 Chamber dimensions: Top plate $=220 \mathrm{~mm}$ (outer diameter) $\times 19 \mathrm{~mm}$ (height)

Bottom plate $=220 \mathrm{~mm}$ (outer diameter) $\times 26 \mathrm{~mm}$ (height)

Optical port of top plate: Diameter $40 \mathrm{~mm} \times$ depth $15 \mathrm{~mm}$

2 Chamber weight: $9.75 \mathrm{~kg}$

3 Chamber Plate material: Stainless steel

4 Internal volume: $629 \mathrm{CC}$

This time-related heterogeneous ice nucleation information will help us in understanding microphysical properties of IN and better quantifying the experimental ice nucleation rates. However, we would also like to point out that the static diffusion chamber described in this article does not allow sampling the aerosols directly from the air.

In the following sections the design and construction of the instrument is outlined, including the different components involved in the experimental set-up, experimental procedure and instrument performance. The instrument performance is validated against literature data, and to demonstrate the application of TGDC experiments first results are presented for ice nucleation onset characteristics of Saharan mineral dust particles. Suggestions for future development are outlined in the conclusion section.

\section{Design of the experimental set-up}

The experimental objectives of this work were to measure the ice nucleation efficiency in determining the onset relative humidity of atmospherically important aerosols for ambient temperature and $\mathrm{SS}_{i}$ conditions. Figure 1 shows a schematic diagram of the experimental set-up. This setup consist of the following major systems: (1) a main diffusion chamber, called as TGDC, where the aerosols are exposed to the desired temperature and $\mathrm{SS}_{i}$ gradients, (2) an optical microscope including an insulated housing to keep the microscope warm at all experimental conditions, and (3) the Environmental Room (ER) which is a walk-in cold room used to lower the temperature of the TGDC (the gradient in temperature is achieved by heating one of the plates relative to this ER temperature), where the ER has a working temperature range from -60 to $50^{\circ} \mathrm{C}$. Other systems include the proportional integral derivative (PID) controller box, which displays the real-time temperature and is also used to control the heating rate of the heating mat, and the aerosol introduction system used to expose aerosols to inside TGDC thermodynamics conditions. The following sections describe the experimental setup in detail. 


\subsection{TGDC design and construction}

The main section of the TGDC consists of two circular horizontal parallel stainless steel plates, with the assembly of the top and bottom plates separated by a $1 \mathrm{~mm}$ thick silicon gasket of width $6 \mathrm{~mm}$. The vertical cross section of the TGDC is shown in Fig. 2 and the important dimensions are described in Table 1. The top plate has an optical port at the center where a glass window of $2 \mathrm{~mm}$ thick has been installed, which allows illumination and observation of the sample by the microscope. The port also houses the microscope objective lens cover tube in which microscope objective lens slides up and down. The bottom plate holds the assembly for introducing the aerosol sample inside the TGDC. Both plates are cooled using an air forced convection heat transfer mechanism generated by the walk-in cold room (referred to as the Environmental Room - ER). For more details about the operation of the ER see Sect. 3. Both plates are ice coated from the inside and in the system their temperatures can be controlled independently. Both plates also have four circumferentially drilled ports which are used to insert resistance based temperature detectors (RTD), and measure temperature distribution across the plates with an accuracy of $\pm 0.1{ }^{\circ} \mathrm{C}$. A heating mat associated with the top plate is used to raise its temperature to the desired value relative to the bottom plate, which is set by the ER. This temperature difference causes gradients in the diffusion of water vapor and heat to develop between the plates. The exponential relationship between saturation water vapor pressure and temperature leads to a $\mathrm{SS}_{i}$ between the two walls with a maximum close to the mid point of the chamber.

One of the benefits of the design of our chamber is that a range of $\mathrm{SS}_{i}$ can be sampled without changing the temperatures of the plates. So, it was desirable to have plates with a large thermal capacity so as to maintain stable temperatures, however, this is contrasted with the desire to be able to lower the plate temperatures quickly between experiments. In choosing the material for the TGDC, consideration was given to the size of the TGDC, the cooling mechanism, the range of humidity conditions, and the number of experiments desired. In the present system, the ER uses a forced convection type heat transfer mechanism for cooling the TGDC. Due to low thermal conductivity of air, the chamber system is designed to operate inside the ER had to have a large mass to enable uniform heat distribution within the chamber so that the system can maintain constant temperature for long periods of time. From the heat equation, Eq. (1), the heat absorbed or lost $(q)$ is related to the mass of the system $(m)$, specific heat capacity $\left(C_{p}\right)$ of the system and the temperature difference $(d T)$ between the system and its surroundings, as (Incropera et al., 2007),

$q=m \times C_{p} \times d T$

From Eq. (1), the choice of material for the chamber system would need to have a large mass and $C_{p}$ value. Also a

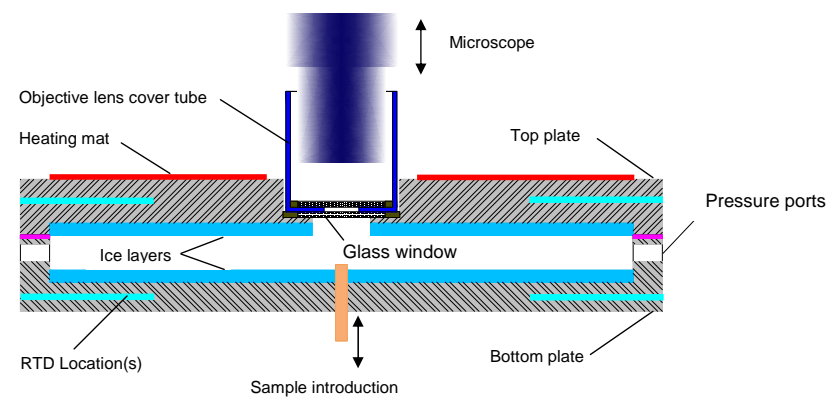

Fig. 2. TGDC experimental geometry with provision for temperature sensor (RTD) locations and a heating mat. The objectives lens of the microscope is raised and lowered inside the objective lens cover tube. While performing the experiment the ice layer on the top plate has been extended towards the center to reduce the inner diameter of the ice layer. Four ports of diameter $6 \mathrm{~mm}$ are drilled diametrically opposite on the bottom plate at 90 degree away from each other for use as pressure-control ports. Specifically, these ports can be used to produce pressure conditions below $1 \mathrm{~atm}$ inside the chamber via pumping.

relatively low thermal conductivity $(K)$ material in order to maintain a uniform thermal distribution on each plate. The materials of choice used for construction of diffusion chambers are stainless steel, brass, aluminum or copper as shown with relevant thermodynamic values in Table 2. From Table 2 it can be seen that the stainless steel $304 \mathrm{~L}$ grade material satisfied above chamber design criteria's and was therefore used as a chamber material.

Various TGDC concept design configurations were simulated using commercially available computational fluid dynamics (CFD) software FLUENT (FLUENT, 2004). This aided in determining the size of the ports (along with the microscope requirements: working distance $=33 \mathrm{~mm}$ and diameter of the objective lens $=34 \mathrm{~mm}$ ), along with determining the effects of each TGDC conceptual geometry on the temperature and $\mathrm{SS}_{i}$ profiles within the TGDC. The final TGDC geometry that met the requirements is shown in Fig. 2. Figure 3 shows the temperature distribution across the vertical cross section. Initially both plates are kept at $-30^{\circ} \mathrm{C}$, and then the top plate is heated to raise its temperature to $-20^{\circ} \mathrm{C}$. A linear thermal gradient between the chamber plates can be observed except near the walls and at the center (the top half of the chamber below the microscope). The non-linearity in the thermal gradient in the later region is due to the small optical port opening of the top plate. It was confirmed that this non-linearity has no effect on experimental results in the lower half of the chamber. See Sect. 4 for more details.

These CFD simulations are further extended to determine the heat capacity of the heating mat used for warming the top plate compared to bottom plate. The choice of the heating mat capacity depends upon the desired rate (at least $1^{\circ} \mathrm{C}$ per minute) of warming the top plate, and the heating mat material upon the exposed temperature and humidity conditions. 
Table 2. Thermodynamic properties of different materials. Steel has high Specific heat capacity $\left(C_{p}\right)$ and density with low thermal conductivity $(K)$ making the material suitable for the chamber development.

\begin{tabular}{llll}
\hline Material & Stainless steel & Aluminum & Copper \\
\hline$K(\mathrm{~W} / \mathrm{mK})$ & 16 & 235 & 400 \\
Density $\left(\mathrm{Kg} / \mathrm{m}^{3}\right)$ & 7900 & 2702 & 8933 \\
$C_{p}(\mathrm{~J} / \mathrm{KgK})$ & 477 & 903 & 385 \\
\hline
\end{tabular}

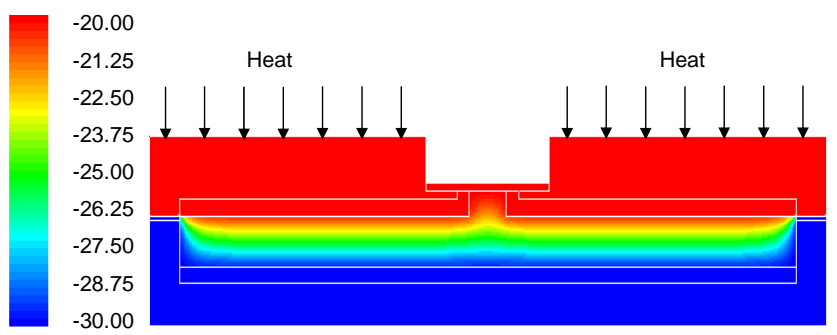

Fig. 3. A steady state temperature distribution calculated using CFD commercial software FLUENT along the vertical cross section of the TGDC. The conditions are initialized with both the plates maintained at bottom plate temperature of $-30.0^{\circ} \mathrm{C}$. During the simulation heat flux is added to the top plate to raise its temperature to $-20.0^{\circ} \mathrm{C}$.

A circular silicone rubber heating mat of $150 \mathrm{~W}$ (Hawco Ltd) was found to satisfy the requirements. The heating mat has an adhesive backing and can operate up to a maximum temperature of $180^{\circ} \mathrm{C}$, and is moisture resistant. They also heat up rapidly and provide uniform heat distribution.

\subsection{Image acquisition}

The ice nucleation phenomenon of aerosol particles once exposed to the determined thermodynamic conditions $\left(\mathrm{SS}_{i}\right.$ and temperature) is observed in real-time using an optical microscope attached to a camera (WATLCL miniature 1/3" colour camera). The microscope requirements were stringent in that high resolution of particles was required at a long working distance. The microscope has a resolution of 5 micrometers with a 10X OPTEM brightfield objective lens of working distance of $33 \mathrm{~mm}$. For illuminating the aerosol sample, the microscope uses cold light to minimize any temperature perturbations inside the chamber below the optical port window: the optical fiber cable transfers the light from the source, powered by halogen lamp $(150 \mathrm{~W})$, with a heat reflecting filter, to the microscope. The images captured by the camera are digitally transferred to a computer which is installed with Euresys Picolo computer frame grabber capable of transferring full resolution color images up to $768 \times 576$ pixels and sequence of images up to the speed of 24 frequency per second which is more than adequate for our nucleation experiments.
The microscope discussed above has operating temperature range of -5.0 to $+60.0^{\circ} \mathrm{C}$. The experiments are carried out at subzero temperatures reaching $-60^{\circ} \mathrm{C}$ of the ER. To prevent the microscope from freezing, an insulation box was designed to accommodate the microscope and maintain at room temperatures. A $20 \mathrm{~W}$ heater was used with $12 \mathrm{~V}$ fan to circulate the air inside the insulating box to obtain and maintain the uniform temperature distribution of $20^{\circ} \mathrm{C}$. A port was installed on the side for wiring to connect to the computer outside the ER room. A small cylindrical port at the bottom side of the box was installed with an objective lens cover tube that allowed a thermal barrier between the insulated housing and the sub-zero temperatures of the TGDC and surrounding ER air.

\subsection{Aerosol introduction system}

The unique feature of the TGDC instrument is that aerosol particles are in a static TGDC environment and ice nucleation is directly observed within the chamber through the optical port. To lower the thermal instability and minimize the possibility of convective currents inside the TGDC, the following approach is taken to introduce the aerosol samples. The particle samples to be investigated are deposited on the Teflon substrate by the method of dry deposition. We do not use any wet atomization process. Initially the particles are deposited on the substrate and using clean compressed air the particles are uniformly distributed across the substrate. The Teflon substrate surface is 100-300 micron thick and hygrophobic, affixed to the top of the copper rod sample holder. This copper rod with the Teflon surface with the aerosols on top (sample holder) is manually inserted into the port in the lower plate directly below the optical port. The other end of the sample holder is connected to a micrometer which is fastened and affixed to the lower plate. When first inserted, the aerosol samples are just inside the lower plate at ice saturation conditions. The micrometer screw is manually operated and each complete turn of the screw raises or lowers the rod by $0.5 \mathrm{~mm}$. A scale revolving with the screw is divided into 50 parts and indicates, therefore, the fractions of a turn in units of $0.01 \mathrm{~mm}$. This way, aerosol samples are raised to different heights within the TGDC through the $\mathrm{SS}_{i}$ and temperature profile, while the temperature of the plates is held fixed. In the vicinity of the aerosol introduction system inside the TGDC, i.e. directly below the optical port throughout the chamber, the temperature distribution is recorded using thermo resistor temperature sensors. The errors in the temperature distribution observed before and after introducing the sampling rod are within the experimental limit, which confirms thermal stability inside the TGDC. 


\section{Experimental methodology and performance charac- teristics}

The stages of the experiment can be conveniently described by referring to the experimental temperature profiles as a function of time shown in Fig. 4. Before an experiment can be performed the two plates of the TGDC are placed inside the ER with inner surfaces facing upwards. A calculated volume of $250 \mathrm{CC}$ of deionized water $(18 \mathrm{M} \Omega)$ is poured inside the cavity of these plates to prepare the ice layer after they are cooled. The thickness of ice layer produced dictates the gap between the surfaces of the two ice layers once these two plates are assembled. For all the experiments a constant gap of $12 \mathrm{~mm}$ was maintained between the ice layers coated on each plate.

Two RTD probes were inserted in the circumferential ports, and the temperatures were displayed using a PID box controller (CAL 3200) situated outside the ER. In addition to this, the ER has two temperature probes: one measures the overall temperature of the ER including wall casing and other is a flying temperature probe (FTP) located inside the ER which measures specifically the ambient air temperature. Both temperatures are displayed on the built-in ER control board. The control board is used to set the target temperature and can be programmed for controlled heating - cooling operations. The control board also records the humidity conditions in addition to temperature inside the ER. These initial temperature conditions of the experiment are shown at the start of period 1 in Fig. 4. The temperature $(T d)$ and $\mathrm{SS}_{i}$ value at any desired height (d) inside the chamber are calculated using the following expressions,

$$
R=d / h
$$

$T d=(\Delta T \cdot R)+$ Tbot

$\mathrm{eid}=\{\mathrm{esi}(\mathrm{Ttop})-\mathrm{esi}(\mathrm{Tbot})\} \cdot R+\mathrm{esi}($ Tbot $)$

$\mathrm{SS}_{i}=\{\mathrm{eid} / \mathrm{esi}(T d)\}-1$

where,

$h=$ the height between the ice layers in $\mathrm{mm}$,

$\Delta T=$ absolute difference between the top and bottom plates temperatures (Ttop - Tbot),

esi(Ttop) $=$ saturation vapour pressure over ice at top plate temperature,

esi $($ Tbot $)=$ saturation vapour pressure over ice at bottom plate temperature,

esi $(T d)=$ saturation vapour pressure over ice at $T d$ temperature.

The saturation water vapor pressure over the ice is calculated using expressions given by Flatau et al., 1992. In this

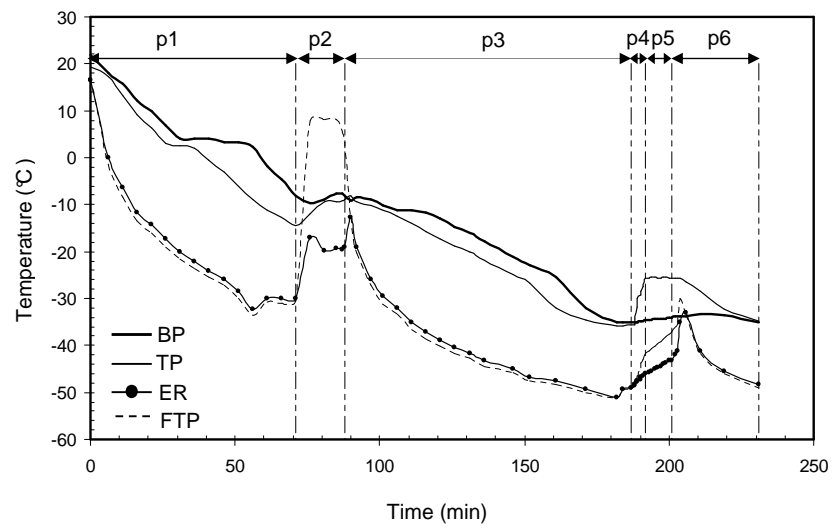

Fig. 4. The experimental temperature profiles of the experimental set-up during one typical ice nucleation experiment. The temperatures are indicated by BP - Bottom Plate, TP - Top Plate, FTP Flying Temperature Probe, ER - Environment Room. The p1 to p6 represent the periods which suitably divide the experimental temperature profiles into various regimes described in Sect. 3 .

typical experiment the desired top and bottom plate temperatures are -25.6 and $-34.4^{\circ} \mathrm{C}$. Using these temperature values and Eq. (5) the maximum $\mathrm{SS}_{i}$ was calculated at midway between the plates, which was approximately $8 \%$. Further using Eqs. 2-4, the percentage relative humidity with respect to ice $\left(\mathrm{RH}_{i}\right)$ can be calculated as ratio of $\{$ eid $\times 100\}$ to the $\{$ esi(Td) $\}$ at any desired height (d) inside the chamber.

The experimental procedure employed is as follows. The plant room generates the filtered cold air that is forced inside the ER. The currents of cold air cool the TGDC system by a forced convection heat transfer mechanism. An interesting feature of the top and bottom plate temperatures can be seen after approximately $30 \mathrm{~min}$. At approximately $4^{\circ} \mathrm{C}$ for a few minutes the plate temperatures are unchanged. This may be due to fact that the density of water is high and heat transfer is via the conduction mechanism rather than advection (bulk motion of fluid due to buoyancy). The ER temperature reaches $-30^{\circ} \mathrm{C}$ after approximately $50 \mathrm{~min}$ and stabilizes. After $71 \mathrm{~min}$ from the start of the experiment the top and bottom plate temperatures reaches -14 and $-9^{\circ} \mathrm{C}$ respectively, and the ER is switched off.

In period 2 the experimenter enters (entry is through double doors, opening one then closing before opening the second door) the ER to assemble the experimental set-up. When the experimenter enters the ER, the room temperature air enters inside the ER which is noted by observing the temperature profile of the FTP. The fixed sensors of the ER located inside the ER wall casing respond slowly to this heat input. The two plates are assembled along with the temperature sensors and the optical glass window. This assembly is raised and aligned below the microscope insulating box in such way that the objective lens of the microscope fits inside the optical 
port of the top plate, as shown in Fig. 2. At the end of period 2 the experimental set-up is fully assembled and the ER is switched on and set to $-50^{\circ} \mathrm{C}$.

Period 3 is the longest period; here the decrease in the temperature values measured by the temperature sensors can be observed. The temperature of the plates decreases almost linearly while the ER temperature decreases exponentially. The ER is switched off when the bottom plate cools by $1.0^{\circ} \mathrm{C}$ below the desired bottom plate temperature. This is performed to so as to be at or close to the target ER temperature accounting for the warming of the plates which occurs when the ER doors and its two windows of $150 \mathrm{~mm}$ diameter are opened.

At the start of period 4 the PID controller is switched on to initiate warming of the top plate to a desired temperature $\left(-25.6^{\circ} \mathrm{C}\right.$ in the present example). At the end of this period the top plate has reached the desired top plate temperature.

The nucleation experiments are performed in period 5, described in Sect. 2.3, during which time the PID controller maintains the target top-plate temperature. The temperature of the top plate remains nearly constant while the bottom plate temperature increases by half a degree. With additional precautions, such as keeping the ER on and programming the PID controller, this rise in the temperature is restrained and the linear thermal gradient inside the TGDC can be maintained for long enough time. This maximum time is related to the sublimation rate of the top plate ice layer. For experiments carried out with large diffusion gradients (at very high $\mathrm{SS}_{i}$, e.g. more than $40 \%$ ) with long periods of time (e.g. more than $60 \mathrm{~min}$ ), it is possible that the height of the center planar lamina of maximum $\mathrm{SS}_{i}$ might shift upwards.

In period 6 the experimental set-up is prepared for the second nucleation experiment. The ER is switched on until the bottom plate cools by 0.5 to $1.0^{\circ} \mathrm{C}$ higher than the desired bottom plate temperature. The end of this period corresponds to the start of period 4 and performing the experimental procedure outlined, the experimental temperature conditions are ready for a second nucleation experiment.

This procedure from period 4 to period 6 can be repeated for performing a third, fourth and subsequent nucleation experiments. To perform another experiment with different desired top and bottom plate temperatures the ER is switched off at the respective temperatures as described in period 3 .

\section{Evaluation of experimental setup}

\subsection{Calibration of temperature in the TGDC}

A uniform temperature distribution was observed at all the locations inside the plates. RTD's are also embedded inside the ice layer of two plates, and a uniform temperature distribution is observed. Simultaneous temperatures are measured of each plate and its ice layer. No temperature differences were observed at these two locations. A series of thermistors were used to measure the temperature field inside the TGDC with a thermal gradient between the plates is applied. The vertical and horizontal temperature profiles recorded agree with mathematically calculated profiles using Eqs. (2) and (3).

In addition to direct validation of temperature profiles with temperature sensors, the profiles were also validated by observing the deliquescence of $\left(\mathrm{NH}_{4}\right)_{2} \mathrm{SO}_{4}$ at its eutectic point of $-19.35^{\circ} \mathrm{C}$ (Braban et al., 2001; Cziczo and Abbatt, 1999). This temperature value is both the eutectic point and anhydrous deliquescence temperature at ice saturation vapor pressure. The experiment is prepared such that both plates are cooled to $-25^{\circ} \mathrm{C}$. By maintaining the plates at the same constant temperature a homogeneous water vapor distribution inside the chamber is obtained. Ammonium sulfate (AS) particles were deposited on the Teflon substrate of the sample holder, and the other holder was positioned on the micrometer. Ammonium sulfate particles raised to the middle of the gap between TGDC, where maximum $\mathrm{SS}_{i}$ would occur if a thermal gradient is applied. The TGDC system is warmed at the rate of $0.25^{\circ} \mathrm{C}$ per minute by operating the ER. The warming of both plates, which are at constant temperature, increases the ice saturation vapor pressure inside the TGDC. Once the TGDC reaches the eutectic point temperature the deliquescence phenomenon is observed. The experiment was repeated eight times to determine the uncertainty. The deliquescence was observed with one standard deviation of approximately $0.4^{\circ} \mathrm{C}$ from the eutectic temperature. Similarly the sample holder is raised to different heights in the bottom half of gap between the plates and observed for the deliquescence. We set the chamber conditions in such way that combination of top and bottom plate temperatures produces the deliquescence relative humidity (DRH) temperature and relative humidity with respect to water $\left(\mathrm{RH}_{w}\right)$ at desired height between the plates inside the chamber. To make it more clear we elaborate this procedure here by using one example. The top and bottom plate temperatures are established in such way that their average temperature is $-22.0^{\circ} \mathrm{C}$ (observed at the mid plane) and produces $83 \% \mathrm{RH}_{w}$, which is $\mathrm{DRH}$ of the $\mathrm{AS}$ at $-22.0^{\circ} \mathrm{C}$ temperature. Initially the AS particles are deposited on the substrate, which is positioned at bottom plate temperature where sub-DRH conditions exists. Slowly the substrate is raised inside the chamber, this exposes the particles to higher temperature and $\mathrm{RH}_{w}$, but below DRH. We found that once substrate reaches near the DRH point, which is in this case is a mid point between two ice layers, phase change is observed. By knowing the height of the substrate from bottom ice layer, we calculated the temperature where the phase change is observed. Please note that temperature varies linearly from bottom to top ice layer, therefore knowing the substrate height from the bottom ice layer one can calculate the corresponding temperature where phase change is observed. Equations (2) and (3) described in Sect. 3 are used to calculate the desired temperatures. Also the temperature calibration was performed with the melting point of ice. The experimental procedure is similar to as observing DRH at eutectic point of AS described above. Instead here we make use 
of the ice crystals deposited on the substrate raised inside the chamber. At the start of the experiment the temperatures of both the plates are $-10^{\circ} \mathrm{C}$ and both are warmed at the rate of $0.25^{\circ} \mathrm{C} / \mathrm{min}$ to reach above $0^{\circ} \mathrm{C}$. When substrate temperature reaches near to $0^{\circ} \mathrm{C}$ the ice is observed to start melting. All results found were very similar with one standard deviation of $0.4^{\circ} \mathrm{C}$

\subsection{Calibration of the $\mathrm{SS}_{i}$ profile in the TGDC}

Ammonium sulfate deliquescence properties can also be used to validate the $\mathrm{SS}_{i}$ profile in the TGDC now that the temperature has been calibrated. The validation was carried out at three different temperature values, $-19.35,-22.0$ and $-28.0^{\circ} \mathrm{C}$, and the experimentally observed DRH values are compared to the literature values of $82.2,83$ and $84 \% \mathrm{RH}_{w}$ respectively (Kanji and Abbatt, 2006; Braban et al., 2001). In Fig. 5 the determined DRH values are compared to the literature including Extended Aerosol Inorganic Thermodynamics Model (E-AIM) (available at: http://www.aim.env.uea.ac.uk/ aim/aim.php, 2008), and are in close agreement. The experimental limitations prevented us from performing deliquescence experiments above the eutectic temperature because ammonium sulfate deliquescence $\mathrm{RH}_{w}$ is less than the ice saturation vapor pressure.

\subsection{Onset ice nucleation properties of Saharan mineral dust}

The TGDC has been designed to study ice nucleation characteristics of aerosol particles. More specifically the process level studies which deals with the understanding of role of mineral surface or active sites, memory effects, surface elemental composition on the ice nucleation. Use of larger size particles (with median diameter of $10-15$ micron) helps us to perform these process level studies, and the current experiment set up provides the opportunity to undertake these studies. Here one can observe the single dust particles for sufficiently long time at various temperature and supersaturation conditions. In this section, we present first results for this new chamber using Saharan mineral dust particles. The mineral dust particles were collected at the surface in association with the African Monsoon Multidisciplinary Analyses (AMMA) 2006 project. The dust samples used in this study were collected from Nigeria. Since these samples were collected at the surface, it is anticipated that only the smaller sizes would have the potential to become airborne. Therefore, sifting of the sample was done using various size sieves to obtain a mineral dust of $38 \mu \mathrm{m}$ or smaller. The theoretical limit of resolution of the optical system is 1.1 micron. Although this high resolution is achievable, but the experimental limitations to collect and deposit the dry particles on the substrate did not allowed us to experiment with these small particles. These mineral dust particles were deposited on the Teflon attached sample holder end during period 5 of the ex-

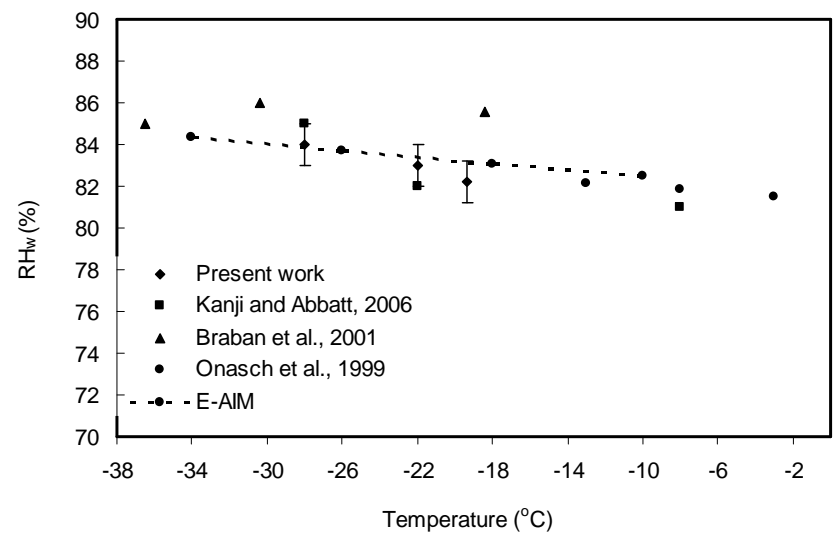

Fig. 5. Comparison of DRH values determined in the present work and the best values from literature (Kanji and Abbatt, 2006; Braban et al., 2001; Onasch et al., 1999) for various temperatures. The error bars are due to the temperature uncertainties in the top and bottom plates, which are within $2 \%$ of $\mathrm{RH}_{w}$.

perimental procedure, as described in Sect. 3. As mentioned, ice nucleation was observed optically and the images were used in conjunction with the recorded profiles (temperature and $\mathrm{SS}_{i}$ ) to determine the onset nucleation $\mathrm{SS}_{i}$. The microscope is focused over the particles deposited on the substrate, and when the ice is formed (the dust particle's reflectivity changes and the ice embryo starts growing) the nucleation event is recorded. We had sufficiently large particles with median diameter approximately equal to 10 to 15 microns, which further helped us to observe the individual dust particles with available magnification and thus any ice formation.

Figure 6 shows an example of images recorded for these dust particles as a function of time recorded by the microscope in a typical single onset ice nucleation experiment. The dimensions of each image, also field of view, are $125 \times 94 \mu \mathrm{m}$. The procedure that is used for mineral dust is to raise the sample holder to pre-determined heights (temperature and $\mathrm{SS}_{i}$ ) for a period of $60 \mathrm{~s}$ at each height. As soon as nucleation is observed on any particle observed in the field of view then onset temperature and $\mathrm{SS}_{i}$ are recorded and that experiment is terminated. A new dust sample is introduced and the experimental procedure is repeated. For Fig. 6a, the mineral dust particles are exposed to $3.2 \% \mathrm{SS}_{i}$ for approximately $60 \mathrm{~s}$ to observe any ice nucleation. No ice nucleation is observed in this period of time, therefore the particles are raised (see Sect 2.3 for more details) to the next higher level of $5.5 \% \mathrm{SS}_{i}$ to observe any ice nucleation. Approximately near $69 \mathrm{~s}$ ice nucleation is observed, shown in panel (b) of Fig. 6. To show further growth of the nucleated dust particle, the $\mathrm{SS}_{i}$ is held constant after onset nucleation is observed at onset $\mathrm{SS}_{i}$. Figure $6 \mathrm{c}$ and $\mathrm{d}$ are shown only for illustration more specifically to show the growth of nucleated dust particle for two subsequent times circled in red. 


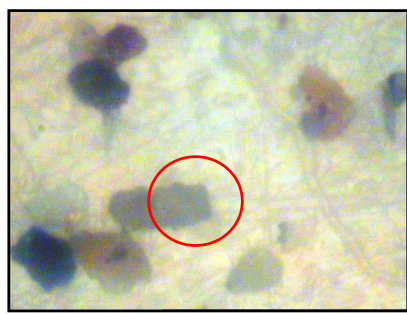

(a) Time $=0$ seconds, $\mathrm{SS}_{\mathrm{i}}=3.2 \%$

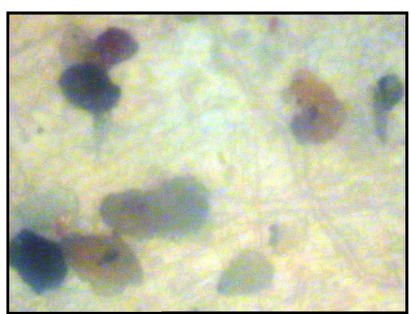

(c) Time $=78$ seconds, $\mathrm{SS}_{\mathrm{i}}=5.5 \%$

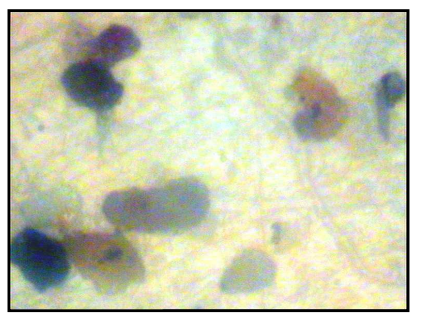

(b) Time $=69$ seconds, $\mathrm{SS}_{\mathrm{i}}=5.5 \%$

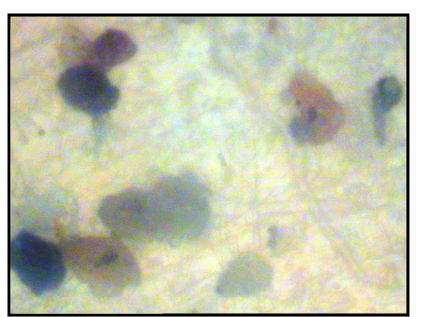

(d) Time $=92$ seconds, $\mathrm{SS}_{\mathrm{i}}=5.5 \%$

Fig. 6. Ice nucleation onset images of dust particles on the Teflon substrate with the aerosol particle undergoing nucleation circled. The total magnification of these images is $938 \times$. The particle circled with red color in panel (a) is nucleated approximately after $69 \mathrm{~s}$, as shown in panel (b). The images in panel (c) and (d) show the successive images of the same dust particles at constant onset $\mathrm{SS}_{i}$. The temperature in Fig. $6 \mathrm{a}$ is $-33.3^{\circ} \mathrm{C}$ and Fig. $6 \mathrm{~b}-\mathrm{d}$ are at $-32.7^{\circ} \mathrm{C}$.

Figure 7 shows the onset ice nucleation $\mathrm{SS}_{i}$ data obtained for the Saharan dust particles in the temperature range varying from -17 to $-33^{\circ} \mathrm{C}$. The area of a data point square box represents the frequency of observing onset ice nucleation for a total of 45 experiments. The statistical distribution of nucleation illustrates a representation of the variability of onset nucleation that exists within the mineral dust sample of 8 particles or less in a field of view. In principle, we can analyse the nucleation of individual dust particles using this system. It is observed that the data points are scattered and the highest frequency varies from 5 to $7 \% \mathrm{SS}_{i}$ which are in agreement with Kanji and Abbatt (2006). These results demonstrate the ability of dust particles to nucleate at low $\mathrm{SS}_{i}$ compared to homogeneous freezing and over a wide range of heterogeneous ice nucleation temperature regime.

\section{Conclusions}

A new Thermal Gradient ice nucleation Diffusion Chamber for ice nucleation investigations has been designed, constructed, and validated. The principle of operation is similar to that outlined by Bailey and Hallett (2002), in that it employs a thermal gradient between two ice-coated horizontal cylindrical plates to produce a $\mathrm{SS}_{i}$ spectrum between them. The unique capability of this new TGDC is that it affords the opportunity to visually record nucleation events of individual particles, whilst the plate temperatures are fixed for the

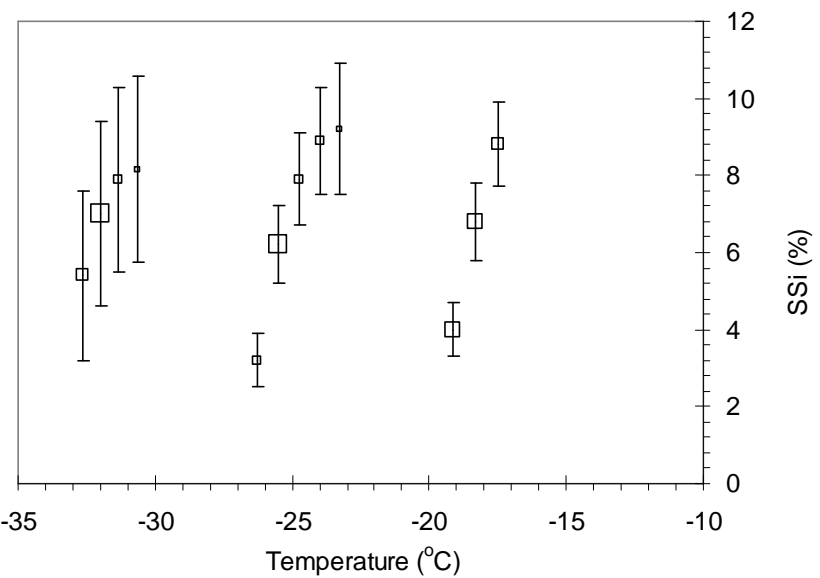

Fig. 7. Plot of onset $\mathrm{SS}_{i}$ as a function of temperature for a Saharan mineral dust sample. The data points shown as square boxes represent where the onset nucleation is observed in which the frequency of onset nucleation event increases with increasing area of the box. In each experiment new dust particles are tested for their onsets, and the error limits represent uncertainty in the $\mathrm{SS}_{i}$. A distribution scatter in the data was not observed because experiments were performed at fixed temperature and supersaturation values. See Sect. 4.3 for more details.

duration of the experiment. This experimental setup allows for stable and well defined conditions for studying nucleation processes with relatively low uncertainty in temperature and $\mathrm{SS}_{i}$. In addition, the temperature and $\mathrm{SS}_{i}$ are well defined for long enough time (period 5 in the Fig. 4) for at least 10 min. The temperature and $\mathrm{SS}_{i}$ profiles developed inside the TGDC were validated by determining the deliquescence relative humidity of ammonium sulfate in addition to direct temperature measurements and CFD simulations. The deliquescence results show that the experimental data agree well with the literature data within the error limits.

Experiments are carried out using TGDC instrument to perform ice nucleation studies of atmospherically important aerosols, here used are natural dust particles. The new TGDC instrument was used to study the onset nucleation of Saharan mineral dust obtained in association with the AMMA project. It is observed that the mineral dust particles nucleated ice over a broad range of $\mathrm{SS}_{i}$ varying from as low as $3 \%$ to $10 \%$ over the temperature regime from -17 to $-33^{\circ} \mathrm{C}$. This broad distribution may be attributed to the variation of mineralogy and surface irregularities over the dust particle surface between different particles. In a follow-on paper, results will be shown illustrating the heterogeneous nucleation capability of dust from various source regions and parameterizations developed to be used in the cloud models. This new TGDC is shown to be well suited to individual particle process studies. Wide arrays of future works are possible with this instrument including addressing the aerosol memory effect of IN with relatively minor updates. 
Acknowledgements. The authors thank Justin Lingard, Sarah Walker and Mike Smith for their lab support and helpful discussions. We also thank Daniel Cziczo and Benjamin Murray for helpful comments. We also greatly appreciate John Hallett for his valuable discussions at the initial stage of this project. Financial support by the School of the Earth and Environment Leeds, UK and Pacific Northwest National Laboratory LDRD funding are gratefully acknowledged.

Edited by: J. Curtius

\section{References}

Bailey, M. and Hallett, J.: Nucleation effects on the habit of vapour grown ice crystals from -18 to $-42^{\circ}$ C, Q. J. Roy. Meteor. Soc., 128, 1461-1483, 2002.

Baker, M. B.: Cloud microphysics and climate, Science, 276, 10721078, 1997.

Braban, C. F., Cziczo, D. J., and Abbatt, J. P. D.: Deliquescence of ammonium sulfate particles at sub-eutectic temperatures, Geophys. Res. Lett., 28(20), 3879-3882, 2001.

Bundke, U., Nillius, B., Jaenicke, R., Wetter, T., Klein, H., and Bingemer, H.: The fast Ice Nucleus chamber FINCH, Atmos. Res., 90(2-4), 180-186, 2008.

Cziczo, D. J. and Abbatt, J. P. D.: Deliquescence, efflorescence and supercooling of ammonium sulfate aerosols at low temperature: implications for cirrus cloud formation and aerosol phase in the atmosphere, J. Geophys. Res., 104(D11), 13781-13790, 1999.

DeMott, P. J., Sassen, K., Poellot, M. R., Baumgardner, D., Rogers, D. C., Brooks, S. D., Prenni, A. J., and Kreidenweis, S. M.: African dust aerosols as atmospheric ice nuclei, Geophys. Res. Lett., 30(14), 1732, 2003.

Flatau, P. J., Walko R. L., and W. R. Cotton,: Polynomial fits to Saturation Vapor Pressure, J. Appl. Meteorol., 31, 1507-1513, 1992.

FLUENT 6: Fluent Inc. Lebanon, New Hampshire, USA, 2004.

Incropera, F. P., Dewitt D. P., Bergman, T. L., and Lavine, A. S.: Introduction to Heat Transfer, Fifth edition, Wiley publications, New York, 1-55, 2007.

Kanji, Z. A. and Abbatt, J. P. D.: Laboratory studies of ice formation via deposition mode nucleation onto mineral dust and n-hexane soot samples, J. Geophys. Res., 111, D16204, doi:10.1029/2005JD006766, 2006.

Knopf, D. A. and Koop, T.: Heterogeneous nucleation of ice on surrogates of mineral dust, J. Geophys. Res., 111, D12201, doi:10.1029/2005JD006894, 2006.

Lau, K. M. and $\mathrm{Wu}, \mathrm{H}$. T.: Warm rain processes over tropical oceans and climate implications, Geophys. Res. Lett., 30(24), 2290, doi:10.1029/2003GL018567, 2003.
Levin, Z., Teller, A., Ganor, E., and Yin, Y.: On the interactions of mineral dust, sea-salt particles, and clouds: A measurement and modeling study from the mediterranean Israeli Dust Experiment campaign, J. Geophys. Res., 110, D20202, doi:10.1029/2005JD005810, 2005.

Mason, B. J. and Maybank, J.: Ice nucleating properties of some natural mineral dusts, Q. J. Roy. Meteor. Soc., 84, 235-241, 1958.

Möhler, O., Field, P. R., Connolly, P., Benz, S., Saathoff, H., Schnaiter, M., Wagner, R., Cotton, R., Krämer, M., Mangold, A., and Heymsfield, A. J.: Efficiency of the deposition mode ice nucleation on mineral dust particles, Atmos. Chem. Phys., 6, 30073021, 2006, http://www.atmos-chem-phys.net/6/3007/2006/.

Onasch, T. B., Siefert, R. L., Brooks, S. D., et al.: Infrared spectroscopic study of the deliquescence and efflorescence of ammonium sulfate aerosol as a function of temperature, J. Geophys. Res., 104(D17), 21317-21326, 1999.

Pruppacher, H. R. and Klett, J. D.: Microphysics of Clouds and Precipitation, Springer Publications, New York, USA, 1997.

Roberts, P. and Hallett, J.: A laboratory study of the ice nucleation properties of some mineral particulates, Q. J. Roy. Meteor. Soc., 94, 25-34, 1967.

Rogers, D. C.: Development of a continuous flow thermal gradient diffusion chamber for ice nucleation studies, Atmos. Res., 22, 149-181, 1988.

Rogers, R. R. and Yau, M. K.: A Short Course in Cloud Physics, Pergamon Press, New York, USA, 150-169, 1989.

Salam, A., Lohmann, U., Crenna, B., Lesins, G., Klages, P., Rogers, D., Irani, R., MacGillivray, A., and Coffin, M.: Ice nucleation studies of mineral dust particles with a new continuous flow diffusion chamber, Aerosol Sci. Tech., 40(2), 134-143, 2006.

Schaller, R. C. and Fukuta, N.: Ice nucleation by aerosol particles: Experimental studies using a wedge-shaped ice thermal diffusion chamber, J. Atmos. Sci., 36, 1788-1802, 1979.

Stetzer, O., Baschek, B., Lüönd, F., and Lohmann, U.: The Zurich Ice Nucleation Chamber (ZINC) - A New Instrument to Investigate Atmospheric Ice Formation, Aerosol Sci. Tech., 42(1), 6474, 2008.

Stith, J. L., Ramanathan, V., Cooper, W. A., et al.: An overview of aircraft observations from the Pacific Dust Experiment campaign, J. Geophys.Res., 114, D05207, doi:10.1029/2008JD010924, 2009.

Turnbull, D.: Kinetics of heterogeneous nucleation, J. Chem. Phys., 18, 198-203, 1950.

Twomey, S.: Pollution and planetary albedo, Atmos. Environ., 8(12), 1251-1256, 1974.

Vali, G.: Nucleation Terminology, B. Am. Meteor. Soc., 66, 14261427, 1985. 